This PDF is a selection from a published volume from the National Bureau of Economic Research

Volume Title: Innovation Policy and the Economy, Volume 6

Volume Author/Editor: Adam B. Jaffe, Josh Lerner and Scott Stern, editors

Volume Publisher: The MIT Press

Volume ISBN: 0-262-10118-1

Volume URL: http://www.nber.org/books/jaff06-1

Conference Date: April 19, 2005

Publication Date: August 2006

Title: Consumer Benefit from Use of the Internet

Author: Fiona Scott Morton

URL: http://www.nber.org/chapters/c0205 


\title{
Consumer Benefit from Use of the Internet
}

\author{
Fiona Scott Morton, Yale School of Management and NBER
}

\section{Executive Summary}

The Internet is one of the most important innovations of the $20^{\text {th }}$ century. This paper discusses sources of consumer surplus that are likely to exist due to the types of sites we see being used online and points to research that quantifies the consumer gains from use of the Internet. I also discuss the problems involved in measuring all the gains from use of the Internet. Websites that make traditional sales generate consumer surplus through availability, variety and convenience to the consumer. Price comparison sites allow consumers to quickly and easily gather price quotes from a variety of sellers, which results in the consumer paying a lower price. Information sites provide information that the consumer can use to pick an appropriate activity or execute a task more efficiently; often these sites save consumers time in mundane tasks such as buying tickets, checking the weather, or getting driving directions. Likewise, matching sites (such as eBay) improve transactions by hugely increasing the quality of the match compared to the local garage sale. While it's clear the Internet increases price competition so that consumers pay less for products, it also improves daily life by increasing the variety, quality and availability of products and information. These gains are particularly useful to people with high transactions costs (busy, rural) and uninformed people. Of course there are existing and potential attempts by firms to hold on to their profits in the face of consumers' lowered search and transaction costs. Corporate responses include lobbying for legal protection, altering product design, restricting the information shared with consumers (obfuscation), and engaging in differential pricing.

\section{Introduction}

The Internet is one of the most important innovations of the $20^{\text {th }}$ century. While Internet penetration has been growing rapidly in the United States and other industrialized countries, and there are many studies 
focused on its growth, there is still much work to be done to understand and measure the benefits of the Internet to the consumer (see table 3.1) ${ }^{1,2}$ Consumers take time to learn how to use any new technology, so the way people are using the Internet changes over time. New consumers are continually discovering the Internet, so the mix of skills and demands among users is changing. Also, in order for the Internet to become useful to ordinary consumers, complementary innovations had to take place, such as in the area of business models. This innovation has been occurring at a great pace, so that now there are many businesses designed to sell products, services, or information that people want to buy or access online. Business model innovation, technological innovation, and learning on the part of consumers imply that the effect of the Internet in 2005 is quite different than it was five or ten years ago. Lastly, quantifying the benefits of the Internet for consumers is particularly difficult because many of the benefits accruing to consumers from using the Internet are extremely hard to measure. Some consumer benefits are more amenable to measurement, and research has been done on those topics.

Internet growth has been astonishing over the last ten years. In 1995, only about 7 percent of the adult American population had Internet access. ${ }^{3}$ By 2005 that number had increased to 67 percent. ${ }^{4}$ About 70-75 percent of the population has an e-mail address. ${ }^{5}$ Until recent years, Internet access from home was through a relatively slow dial-up modem, making it time-consuming and difficult to do anything complex online, such as shop. Now the penetration of broadband Internet access at home in the U.S. is up to 55.5 percent, and many more consumers, 80 percent, have access to high speed Internet connections at work. ${ }^{6}$ The pace of broadband growth in 2004 was an incredible 36 percent. While this torrid pace of growth is almost certain to diminish, it is nevertheless clear that consumers are enthusiastically adopting this new technology. There are different rates of adoption across different demographic groups, of course. For example, the elderly are less likely to use the Internet than the nonelderly. Minority consumers are also less likely to have access to the Internet.

This paper will discuss sources of consumer surplus that are likely to exist due to the types of sites we see being used online. Where possible, I will discuss the research that has been done to quantify the consumer gains from use of the Internet. I will also discuss the problems involved in measuring the gains from use of other sites. The consumer surplus gains from using the Internet likely do not fall evenly across the 


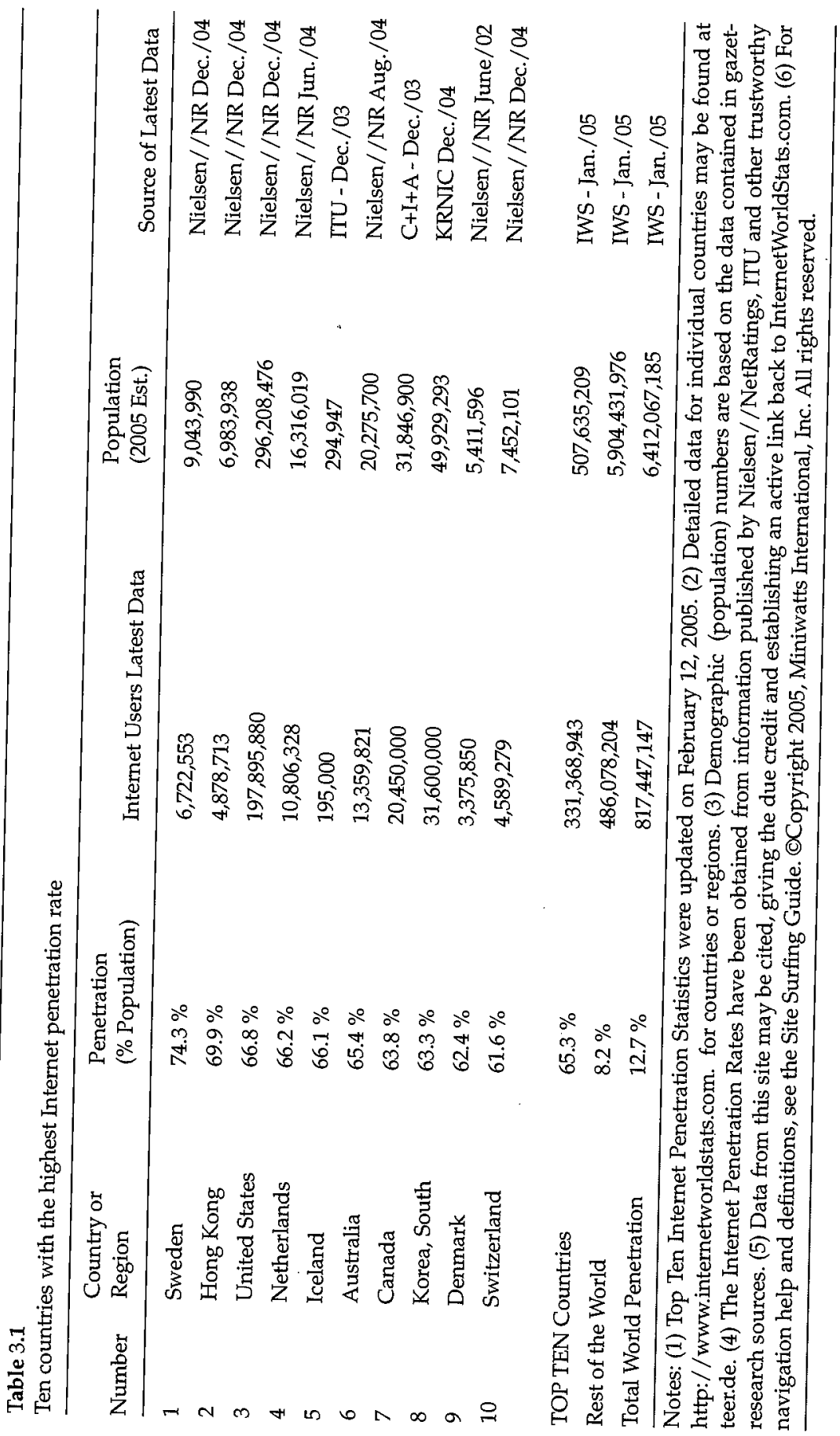


population, but accrue disproportionately to certain demographic and psychographic groups. I will cover the small amount of research that has attempted to examine the distribution of gains from the Internet.

Maintaining and increasing the consumer benefits from use of the Internet is an important policy goal. There are not many threats to consumers' ability to capture the gains from Internet utilization. However, I will discuss some industries where state-level lobbies are attempting to protect local merchants from online competition. I will also consider existing and potential attempts by firms to hold on to their profits in the face of consumers' lowered search and transaction costs.

\section{How Does the Internet Generate Consumer Surplus?}

To be useful, the Internet needs complementary innovation. The complementary innovations that matter in this instance are business models that allow online access (the ISP) and provide the goods, services, or information the consumer wants (websites), using some convenient method of payment. Some of these business models are well-known, such as a subscription, and some are more novel, such as Priceline's name your own price, or Google's automated auctions for ad placements. ${ }^{8}$

\section{Traditional Sales}

Most simply, a website may be run and funded by a single organization that puts information about its operations on the site, or sells its own products on the site. Examples of retailers that fall in this category would be gap.com, continental.com, and godiva.com. Conceptually, this is no different than the way a company operates an existing catalog, phone line, or bricks and mortar store: managers compare the benefit to the corporation of creating and running the site to the cost of the site. Note that the criterion for operating a website is not necessarily that it is profitable in a free-standing way, but that having it makes the entire corporation better off. The Internet can provide significant cost savings to a company by, for example, reducing the need for staff to give directions, hours, or product specifications. Likewise, the Internet may stimulate demand, for example, by providing a convenient sales channel that stocks uncommon sizes of garments. Therefore, it is not surprising to find that these firm-specific sites are extremely common. Equally important for the generation of consumer surplus, are the 
analogous government and nonprofit sites. This category would include, for example, the State Department website that contains passport application forms and a list of required supporting documents, or a church website with directions, service times and an activities calendar. ${ }^{9}$ Consumers using government and nonprofit sites face much lower transaction costs for obtaining the information or product they need. Rather than visiting an office and waiting in line, or misunderstanding phone instructions or dates, consumers can obtain the information they need at any time of day without leaving their home, and examine it at their leisure. Similarly, consumers may face lower transactions costs in finding information about a for-profit firm and its products and purchasing particular items, such as clothing or airplane tickets, through not having to spend time on the phone or make a physical trip to a store.

Do any of these sites represent innovation, given that the business model they use is simple and well-known? For example, the innovation in gap.com and godiva.com is clearly almost entirely in doing the shopping online. I would argue there is important innovation in this category in several areas. First, there are products themselves that could not exist in a predigital age. For example, photo sharing and printing sites such as ofoto.com allow a consumer to edit, print, and importantly, share photographs. The firm covers the cost of the site by selling the consumer its products: prints, calendars, photo albums, etc. Digital music files are likewise a new product that can be distributed much more cost-effectively through the Internet. Digital music therefore represents a new product both in content and in distribution channel. ${ }^{10}$

Second, there are sites where the business model requires so much information, it would be infeasible to execute in a paper world. Grocery shopping online does not at all resemble the available pre-Internet substitute, namely a local store with a person who shops and delivers the food. The Internet allows for the huge "catalog" (SKU list) of the supermarket to be efficiently and accurately presented to the shopper, who can place a precise order using this huge catalog at a very low transaction cost. The Internet's ability to transmit lots of data underlies the business of Amazon.com and its competitors also, where the cost of maintaining a physical store to hold the whole "catalog" of books would be prohibitive. Instead, centralized inventory and individualized delivery are an attractive alternative. It appears that the software and logistics needed to support profitable online shopping and delivery were not so easy to invent, as evidenced by the initial failures of 
Peapod and Webvan, and Amazon's early losses. Peapod is now owned by Ahold and is operating successfully in many markets in the eastern U.S. ${ }^{11}$ Amazon was earning positive profits on its book sales by $2002 .{ }^{12}$

One cost to consumers of this business model is that the consumer must give the business some personal details in order to pay for an item or have it shipped correctly. This may expose the consumer to costs in the form of unwanted e-mail, fraud, or identity theft. These problems do not appear to be halting the growth of transactions on the Internet, yet they remain a concern for users and presumably make the online market smaller than it would otherwise be.

\section{Price Comparisons}

A set of websites that represent a business innovation are those that attract consumers by comparing and contrasting information on products of multiple firms. These sites do not sell the products themselves, but rather generate leads for the retailers of the goods and charge for those leads in order to finance operation of the site. This type of business model creates value for the consumer by sharpening competition among products. A consumer can compare features side by side, read reviews or third-party ratings, and, importantly, compare prices without searching separately at each (online or physical) store. Examples of this type of business model include price search engines ("shopbots") such as dealscan.com or mysimon.com. Ellison and Ellison (2004) describe the operation of such a site (pricewatch.com) and estimate extremely large own-price elasticities of demand that result when a large fraction of consumers use the site. Consumers become extremely price sensitive when, at essentially no cost, they can compare homogeneous products across retailers and choose the one with the lowest price. Websites of this type often specialize in one product, such as term life insurance (quickquote.com) or travel (orbitz.com). Such specialization allows for more accurate comparisons across providers or for the maintenance of a specialized database for the specific product.

A number of the sites that focus on finding low prices for consumers are principally interested in having the consumer compare the local retail price with a single online price. Autobytel.com in the new car retailing industry fits this description (Scott Morton, Zettelmeyer, and Silva-Risso (2001)). A consumer goes to the autobytel.com site and enters the make and model of car she is interested in and her contact information. An autobytel.com affiliated dealer then contacts her with a price, 
which she can compare to the price offered by her local dealer. Scott Morton et al. (2001) show that consumers who use this Internet service to buy a car pay less than other buyers. 1800contacts.com thrives off of competition with local retailers in the contact lens business, as does casketsonline.com in casket retail. Clearly consumers can benefit from the profusion of this business model across products because it helps them search for low prices more cheaply and quickly. ${ }^{13}$ More subtly, also, this type of site can help consumers arbitrage across products or across markets. For example, on a car website a buyer can learn that the Toyota Highlander and Camry are built on the same chassis and therefore are closer substitutes than one would guess by mere visual inspection. A book buyer can shop at a UK or Indian book retailer and pay the lower prices set by publishers in those regions.

\section{Information}

A major source of business model innovation on the web has by necessity been concentrated in websites that are not selling consumers a good or service and therefore cannot mark up a sale. Rather, these websites have information of interest to consumers but not directly related to a purchase. Information providers such as these must support their business in some way, and generally fall into one of two categories: advertising supported businesses or subscription based businesses. Interestingly, in the U.S. the market has not yet found a way to make micropayments feasible, as, for example, has been done by NTT DoCoMo's i-mode in Japan. ${ }^{14}$ A standard for micropayments would be a major business model innovation as it would provide another option for sites such as these to earn revenues, and therefore likely increase their number and diversity.

Examples of sites that supply information but that sell advertising are weather.com, mapquest.com, and edmunds.com. Notice also that all of these sites contain innovations and improvements compared to pre-Internet information. Weather.com is much better than TV weather because of the user's control over which piece of content to view. It allows a consumer to learn weather over a time frame of her choice and a geographic location of her choice, instantly. Mapquest provides maps, again for the geography of choice instantly, and also directions which can be mapped, printed or used electronically. Edmunds online has up to date invoice prices for particular options on particular versions of cars in particular regions. Such a dataset has far too many cells to think 
of printing it as often as the information is updated and changed. Prior to the Internet, consumers purchased a hardcopy of approximate and dated information or exerted some effort to order a fax of an invoice price from Consumer Reports or watch TV at a particular time. The Internet allows consumers to access extremely timely information that is very specific to their location or product choice. Consumers also must view the ads that support the sites, from which some may get disutility. However, the Pew data show that American Internet users go to these information sites frequently, so any advertising disutility appears to be more than offset by the ability to get useful information. ${ }^{15}$

Another type of content website that is prevalent online caters to a particular cultural or hobby group. For example, lasculturas.com, hispaniconline.com (Hispanic culture sites), or rscds.org (the Royal Scottish Country Dance Society) fall in this category. This type of site provides narrowly tailored information to a group with shared tastes and often lets users communicate with each other. The users of such a site may not be in a physical community with enough others of similar taste or background to be able to obtain such information locally. Sinai and Waldfogel (2004) make this point and demonstrate that users who are racial minorities in their cities are more likely to use the Internet, which suggests they gain disproportionately from it. These sites are an innovation over the pre-Internet era when a person would have to pay high costs (travel, phone) to obtain the information, or receive it in a less powerful format, such as a newsletter. For example, the Pew project finds consumers gain more from pre-existing membership in a group when using the Internet as a communications medium. ${ }^{16}$ Personal commentary or reflections online, "blogs," might fall in this category too, as they are usually of interest only to people with specific political, artistic, etc. interests who may not be geographically nearby. An advertising revenue model is a clear fit for such an enterprise, business, or organization because of the demographic or taste similarity of its users.

Sites that provide information such as the ones above are also sometimes supported by subscription revenue rather, or in addition to, advertising. Examples include espn.com, consumerreports.com, and financialtimes.com. All three sites have a great deal of free content (supported by advertising in the case of ESPN and FT, or by mission in the case of the nonprofit Consumer Reports). However, all three also charge subscription fees for premium content, such as the ability to search the archives of the site, or access to special data. ESPN charges 
consumers for premium content (ESPN insider), such as particular statistics, real-time information, wireless updates and so on. ${ }^{17}$ The digitization of the content allows for 'new goods' in the form of searchable archives (much easier to use than a stack of old magazines), breaking news, video clips, and fantasy sports games. The accurate and timely information on these various websites help consumers choose the best products, activities, or driving routes for their tastes, or raise the value of their leisure time.

\section{Matching}

Finally, there are websites designed to let consumers transact or communicate with each other. The websites provide a common platform upon which consumers can find each other. The larger the number of other users of the platform, the more likely a user can find the perfect match, whether that is a toy for a child on eBay.com where millions of Americans sell the contents of their attics, or a date on match.com, a leading dating site. There is substantial research that models competition between these matching sites, or platforms, and analyzes the fee structure of these platforms. ${ }^{18}$ Most simply, platforms can charge a participation fee to all users. However, platforms can also charge different fees to the different sides of the market. Armstrong (2002) shows that fees are likely to be higher for the side of the market that gains more from the interaction, and higher for access to users who only use one platform (e.g., read only one newspaper). Transactions costs may also help determine who pays the fee, such as eBay's choice to charge sellers who are likely to be engaging in many small transactions. Hagiu (2005) shows that consumers' taste for variety affects platform pricing structure. Of interest in this paper is the finding that an open platform, one that charges no fees, is not necessarily welfare-maximizing because it may not have enough of both "sides" to create a lot of trade. A monopoly platform can subsidize access to the scarce side by taxing the abundant side and therefore generate more trade, and potentially
more surplus.

As a mechanical matter, matching sites can and do charge by the transaction (eBay.com) or by subscription (match.com). They can also support themselves with advertising, as petfinder.com does. While garage sales and local bars performed these matching activities before the Internet, they were clearly not as efficient because of their 
requirement of physical presence, which meant small numbers. Now a person with niche tastes, such as demand for vintage Barbie dolls or a particular breed of dog, can locate and purchase the exact item of interest at low transactions cost.

\section{Communication}

Thus far the paper has not discussed communication with friends and family by e-mail. This is by far the most popular activity online, and surveys show it is highly valued by users. ${ }^{19}$ Eighty-eight percent of Internet users send and receive e-mail regularly according to Census data. ${ }^{20}$ The benefits of sending and receiving mail from family, friends and organizations will be somewhat offset by the costs created by spam. The consumer must evaluate and safely delete unwanted e-mail, and this clearly takes time. However, by revealed preference, consumers would rather have e-mail with its current imperfections than not. It is not clear how to measure the amount of consumer surplus this communication innovation creates. The price of broadband access is a lower bound on consumers' willingness to pay, judging from the rapid growth of that technology and the central position of e-mail as an Internet activity. But consumer gains could, of course, be considerably more.

While not central to the topic of this paper, it is interesting to note that there is a debate in the psychology and sociology literatures about whether the social patterns caused by the availability of e-mail and the Internet are good or bad for consumers. Nie (2001) points out that surveys show that Internet users spend fewer hours socializing with household members (UCLA study discussed therein and his own work (2004)) and therefore the Internet may reduce interpersonal interaction and communication. Howard et al. (2001) says that "use of e-mail helps people build their social networks by extending and maintaining friend and family relationships." Certainly, lowering the cost of geographically distant communications may reduce the strength of local networks. These might be social, of the types mentioned above, or commercial.

The communication aspects of the Internet may have an impact on markets by easily enabling communication, and perhaps allowing the development of a relationship, with a distant vendor, for example. Consumers may move purchases to retailers they have come to trust in distant locations; likewise a merchant can develop relationships and a reputation with consumers in distant locations. 


\section{How Much Better Off Are Consumers?}

\section{Prices Are Lower}

Some aspects of Internet use are fairly straightforward to measure and have been measured by researchers interested in the productivity gains generated by the Internet and IT more generally. The first place consumers gain is in the application of the Internet to the operations of firms, and the resulting efficiency on the part of firms. When firms have lower costs, competition delivers lower prices to consumers. For example, the Internet allows dispatchers as well as users of trucking services to view in real time the location of the trucks on the roads. Accurate information allows the user to plan production precisely for the arrival time of the truck, and allows the dispatcher to plan on what other loads might be picked up by that truck..$^{21}$ Real estate listed on the Internet has shorter vacancy times and therefore lower average rents can be charged and still cover costs. ${ }^{22}$ Aircraft and car repair technicians can look up repair instructions on the web faster and more accurately than by paging through stacks of manuals. Such lower costs feed into the overhead or labor needs of firms, and from there into the prices consumers pay.

We have measures of U.S. productivity gains in the sectors that have purchased information technology. Stiroh (2002) estimates that during the 1990s U.S. productivity growth increased by two percentage points in IT-using sectors. National accounts report how many dollars firms spend on information technology. Note, however, that they do not tell us how firms are using the technology, e.g., operating machine tools, accessing the Internet, communicating while on the road, linking with suppliers' production systems, etc. Therefore, the large increase in productivity growth documented by Stiroh (2002) can only be attributed in part to the Internet.

Consumers see the gain directly when they use some of the Internet sites described above. These gains have been measured by various researchers and are substantial. For example, Brown and Goolsbee (2002) show that the prices of term life insurance fell by 8-15 percent after consumers were able to easily search online and compare firms' policies. Scott Morton, Zettelmeyer, and Silva-Risso (2001) show that shopping online for a new car results in a consumer paying 2 percent less for the car, which is about $\$ 450$ for the average car, and represents about one quarter of the average dealer margin. As noted above, Ellison 
and Ellison (2002) demonstrate that the effect of the price search engine, pricewatch.com, is to dramatically increase the rewards of posting the lowest price. They find this extreme competition generates margins for computer parts of about two percent over marginal cost. Brynjolfsson and Smith (2000) examine the book market and find that online books sell for 9-16 percent less than the same offline books, depending on whether taxes and shipping are included. However, Clay et al. (2002) find no difference between online and offline list prices for books, but they do find higher total online prices once shipping is included.

Of course, there are still high prices to be found online. Baylis and Perloff (2002), Baye, Morgan and Scholten (2004) and Clemons and Hitt (2002) show that there is considerable and persistent price dispersion online, even for homogeneous goods. It is not clear how many consumers purchase at these high prices, but we would expect the number to be greater than zero or the firms could not justify posting high prices.

Note that new cars, books and computer chips have a common characteristic; there is largely no problem with unobserved quality of the product itself. Thus, merchants can compete without the consumer needing to physically inspect the product. However, for a product such as collectable baseball cards, there is the possibility of quality that is unobservable to an online buyer. When quality can be unobserved or mis-represented online relative to in a physical store, we would expect to see lower online quality and price. This is what Jin and Kato (2004) find in their data: the quality of baseball cards purchased on eBay is lower than the equivalent offline purchase (and price is insignificantly lower). The existence of online unobserved quality reduces the benefit of shopping online, and indicates that online purchases will be primarily for goods with observable quality. In line with this prediction, Jin and Kato find that online markets sell far more graded baseball cards (which have certified quality) than traditional retail stores, who mostly specialize in ungraded cards. In addition, since trade in many products will be limited without certification of a good's quality, the Internet will cause growth in third-party certifiers. Jin and Kato document that this has happened in the baseball card market. Another example is auto sales on eBay, where eBay has created several programs designed to protect buyers from misrepresentation of quality. eBay also encourages sellers to get a used car inspected by an independent third party, SGS Automotive, before listing it. ${ }^{23}$

In addition to lower prices, increased variety benefits consumers. Brynjolfsson, $\mathrm{Hu}$ and Smith (2003) estimate large consumer surplus 
gains from the access of consumers to the very large catalogs of books provided online. They point out that in the year 2000, the Amazon catalog alone was 23 times larger than the typical contents of a book superstore, which gave consumers a huge variety of books to choose from. Likewise on eBay or iTunes there is a vast variety of products to choose among, which likely increases consumer utility.

\section{Daily Life Is 'Better'}

Researchers may think the impact of IT is hard to measure in the business sector, however, this is nothing compared to the problem in the consumer sector. Consumers, I argue, get a considerable fraction of the gains from the use of the Internet in the form of less time spent looking up phone numbers, queuing, getting lost, determining opening hours, doing routine shopping, choosing the wrong activity given the weather or the train schedule, and so on.

How might one measure this potential improved "daily life efficiency?" One option might be a detailed time study of how people spend their days. Several different studies report time studies that include use of the Internet. Dryburgh (2001) finds that Canadians who use the Internet spend less time watching TV, reading, sleeping, and doing leisure activities at home. A Swiss study (Franzen 2003) found that the Internet did not cause people to spend less time on social activities, but did cause less TV watching. Anderson and Tracey (2001) analyze a UK time study and find that people who gain access to the Internet spend significantly less time on hobbies, games, and musical instruments. If the Internet is making people's lives "better" by saving them time, we should see them spending more time on leisure and hobbies, and less on getting lost, queuing, and shopping. Instead, these studies find consumers spend less time on leisure activities, which does not suggest there is a measurable efficiency gain for consumers.

It may be, however, that the efficiencies generated by the Internet, are by their nature extremely hard to measure with a time study. For example, suppose the Internet reduces the need to queue in the bank because banking can be done online. Will a time-study have enough detail so that a person can record that decrease in time spent banking? It is difficult to measure when a person enjoys lunch with coworkers instead of using part of the lunch hour to queue at the bank. Likewise, it seems unlikely that a person would report getting lost on the way to a dinner party as a separate activity from the leisure activity of socializing with 
friends. Some pursuit of hobbies may occur online and therefore fall into both the Internet and leisure category: a person can use a chatroom to discuss a sports team with other ardent fans, or read about the latest technology for bicycle racing on an enthusiasts' website. So there is likely to be major measurement error in time use surveys that are not going to allow us to measure all the gains from using the Internet that we would like to.

There are other improvements in daily life due to the Internet that don't have a time impact at all but rather a quality impact. For example, a person can choose to go skiing or play tennis in the right weather because of her ability to learn the weather forecast more easily. A consumer can buy the perfect gift for her spouse on eBay, rather than being constrained by what is in the local shops. More generally, a consumer's shopping can be in the types of stores she finds fun and enjoyable; the shopping that is routine or unpleasant can be done online. A consumer can listen to her favorite radio show after it aired by going online, rather than having to listen to a substitute entertainment product; in this way the Internet makes doing the dishes more pleasant. There is no hope of being able to measure the amount of consumer surplus generated from these Internet uses. The cost of Internet access is a lower bound to the gain that consumers realize from using the Internet, but it seems clear that the willingness to pay is substantially higher than the cost of subscribing to an ISP.

Support for quality and quantity efficiencies of using the Internet comes from data collected by the Pew Internet \& American Life Project, and also a Harris poll taken in January 2004 (\#4). ${ }^{24}$ In that poll, consumers listed activities for which they used the Internet "often" or "very often." Sending and receiving e-mail was clearly the top activity (67 percent), followed by doing research for work or school (45 percent). However, 15 percent or more of users chose an assortment of activities that are likely to be quality enhancers, time-savers, or money-savers: getting information about products or services, getting information about hobbies or special interests, checking news and weather, shopping online, paying bills, financial management and investing, making travel plans or arrangements, and obtaining information about health or disease. The Pew data show that on a "typical" day millions of American adults use the Internet to get news, check the weather, research a product before buying it, get travel information, get health information, and buy products. ${ }^{25}$ These findings provide evidence that consumers value the "daily life efficiencies" available through the Internet. Because 
the poll was taken relatively recently compared to other data researchers have used, more sites may have been available to respondents, and considerable consumer learning may have taken place.

\section{Distribution of Gains from Using the Internet}

The gains from using the Internet are unlikely to be evenly spread across consumers. The research that has been done on this topic demonstrates that certain groups benefit disproportionately from using the Internet. For example, in Scott Morton, Zettelmeyer, and Silva-Risso (2003) the authors document that the average minority consumer pays 1.5 percent more for a new car than an equivalent white consumer. In contrast, minorities who use the Internet do not pay a premium relative to white consumers. In this case we see that the benefit from using the Internet falls disproportionately onto minority shoppers who use the tool. Using survey data, Zettelmeyer, Scott Morton, and Silva-Risso (2005) show that consumers who are poor at bargaining benefit the most from collecting information about the car they want to buy. The information appears to help this group bargain more effectively; for consumers who enjoy bargaining, the same information is not associated with a reduction in transaction prices. Similarly, Pauly et al. (2002), find evidence that the introduction of Internet search functions for health insurance disproportionately benefits low-risk consumers. For this group, search costs outweighed search benefits prior to the Internet.

Because the Internet allows consumers to share tastes which might be rare in the local population, it particularly benefits consumers in rural or sparsely populated areas, who might have more difficulty physically interacting with people of their tastes. Likewise, a consumer who represents a cultural or ethnic minority in her city will be able to interact with people of her culture or ethnicity online, and thereby compensate for her location (Sinai and Waldfogel (2003)). Analogously, people who are geographically far from their social network, perhaps because they moved away from college friends, will find the Internet especially useful. In this same category are Internet users with disabilities who can find others with similar problems and interests; Taylor (2000) finds that these people are more likely to use the Internet, and feel more connected and more informed because of their Internet access. ${ }^{26}$ In short, minority consumers of all kinds are likely to benefit disproportionately from use of the Internet. Use of the Internet is also high for consumers who are short of time during the work day in which to perform routine 
tasks (Lohse et al. (2000)). This is hypothesized to be because consumers like those in two-career families and professionals with long hours find their time constraints relaxed by online shopping, banking and communication. The Pew data show that adults aged 30-49 are most likely to shop for groceries and other products online, which is consistent with Lohse's assertion. ${ }^{27}$

\section{Corporate Response to the Internet and Policy Implications}

One would expect a strong corporate response to an innovation as important as consumer use of the Internet, and some aspects of such a response might raise potential policy issues. The most important and obvious challenge to existing firms are the websites discussed above designed to create price competition between bricks and mortar and web retail outlets (e.g., autobytel.com, 1800contacts.com). These businesses make less profit when consumers switch to lower priced alternatives online, and so they have an interest in making such switching more difficult. The FTC identified some of the industries that may be trying to obtain protections from their states. These include funeral homes, wine distributors, auto dealers, mortgage brokers and contact lens retailers. ${ }^{28}$

The FTC position is that state regulations that establish entry barriers in particular geographic markets will lessen competition from Internet providers. "The Federal Trade Commission today released a staff report concluding that e-commerce offers consumers greater choices and more convenience in the contact lens market." "In contact lenses and other industries, barriers to e-commerce can deprive consumers of the benefits of increased competition," said Timothy J. Muris, Chairman of the FTC. ${ }^{29}$ The FTC came to a similar conclusion in its study on wine-shipment bans. ". . e-commerce offers consumers lower prices and more choices in the wine market. . ." ${ }^{\prime 30}$ Several states have laws that require caskets and other funeral merchandise to be sold only by a licensed funeral director of that state. Licensing usually requires the applicant to have a mortuary science degree, pass an exam, and perform a certain. number of embalmings. This type of entry barrier makes it more difficult for online casket retailers to compete in that state, and, therefore allows existing funeral homes to exercise any market power they may have. However, many of the laws the FTC is concerned about are being challenged by Internet retailers. Caskets, wine, and auto retailing, for example, are active areas of litigation. 
It should also be noted that there are efficiency justifications for offline retailers to want protection from online retailers. In some cases a retailer provides a service for which neither shopper nor manufacturer explicitly compensates the retailer. For example, perfume retailers provide samples for consumers to try. If an online retailer need not bear the cost of providing the service, it can sell the perfume for less while free-riding on the offline retailer's demand-enhancing service. The offline retailer would normally cover the cost of the service with the margin on the product it sells, but now sells less due to competition from the online seller. Online sales can therefore cause an offline retailer to cease promoting a manufacturer's product, which may be to the detriment of the manufacturer. Carlton and Chevalier (2001) discuss this case and show that manufacturers may not permit their perfumes to be sold online at all, or may offer them online at only high prices in order to preserve incentives for physical retailers to provide service. However, this externality problem can be solved with policies at the manufacturer level and should not normally require a policy response from government.

The second response that deserves attention is the case where firms attempt to obfuscate their prices or product characteristics. Firms whose products are sold through price comparison engines have a strong motive to appear at the top of the list with an apparently low price, while somehow managing to charge the customer more than the displayed price. This may occur with legitimate effort by the firm to persuade the consumer to upgrade to a higher quality version of the product or buy optional extras. It may also occur, for example, through being perpetually sold out of the item, thus forcing an upgrade to get a product at all, or offering 'regular' shipping that takes a month, thus requiring the customer to pay for expedited shipping. Ellison and Ellison (2004) demonstrate how this occurs in the computer parts market. Buyers who telephone to order the product with the low price in the price search engine are convinced by the seller that they need a higher-quality product. This behavior results in estimated cross-price elasticities that are negative: lowering the price of the "low quality" product does not steal sales away from the "high quality" product, but rather increases them. Firms thus have an incentive to create a low-quality product (features, delivery, warrantee, etc) that no one will actually want to buy but will draw sales to their site through the price search engine and some small switching cost once the customer has arrived at the site. Importantly, the low-quality features that will 
successfully draw consumers to the site must be hard to discern through a search engine.

Differential pricing, or selling the same good at different prices to different consumers, is well-known and effective way for a firm to generate profits. The cost of making multiple versions of a product is often very low for information goods and services sold online. So we may expect to see more of this tactic used by firms in order to share in the surplus generated by the Internet. Subscriptions and unit prices can easily be varied in their content, length, durability, power and so on. For example, a piece of software can be more or less powerful; a DVD can be durable, or can self-destruct within a few days; a digital tune can be copied a certain number of times. By combining durability and other features very carefully (using information on shopping habits or tastes of consumers) so that differential pricing is optimal, a producer can capture more profit.

Another interesting effect of the Internet worth noting is that consumer to consumer transactions cause the effective durability of many goods to increase. A used wooden train set or a ski rack might once have sat unused in an attic, but is now re-sold on eBay. This sale will often replace the purchase of a new good by the consumer who buys it, and this is clearly a cause of concern for firms that sell durable goods. One option for the manufacturer is to raise the price of the train set (provided it has some market power) given that consumers take into account its durable nature and the liquid Internet market. Because consumers can foresee that they will resell the product, consumers will rationally pay the higher price. Chevalier and Goolsbee (2005) find this to be the outcome in the textbook market. It may also be the case that when the second-hand market is large, the firm is left selling to that fraction of consumers who particularly value new goods. Thus the firm can set the price for the new good higher for yet another reason; differential pricing to high valuation consumers.

A product such as a ski rack has multiple components. When part of it becomes more durable due to the Internet, one response might be for the firm to alter the level of profit margin across components. For example, the base of a ski rack fits onto the car and therefore must be specific to the car's model and year. This makes the base depreciate over time because the buyer must have a car it fits. When the firm's revenues fall due to fewer sales of new attachments (and more used attachment purchases), the firm may raise the margin on the depreciating good, the base. It will attempt to extract its profit on the base since 
it can sell the good each year to consumers with a new car. However, suppose higher valuation consumers buy more attachments. In this case the firm would want to engage in differential pricing by placing a markup on the attachments rather than the base, but the durability of the attachments may create a countervailing force against this strategy. There could clearly be cases where the attachments depreciate (printer cartridges) and the base good is durable (printer). In this case, the firm has an incentive to place the markup on the cartridges to engage in differential pricing; quantity metering effectively causes heavy users to pay a higher total price than light users. In contrast to the first example, this strategy is not harmed by the increased durability of the printer.

The analysis in Bulow (1986) suggests that firms with market power optimally choose durability levels to maximize profits. When durability increases exogenously due to Internet markets, perhaps firms will act to offset the effect of the Internet by reducing the durability of their products. The existing empirical literature has not found much evidence of this. However, the Internet may be too new an innovation to have yet caused measurable changes in product design. An interesting topic for future research may be an examination of whether firms whose products have become more durable due to the Internet raise prices for their neoclassical forward-looking consumers, or whether they decrease durability instead.

\section{Conclusion}

The Internet is creating huge value for consumers in the U.S. and around the world. While there are some costs to using the Internet, primarily spam and the threat of fraud or identity theft, in the main the Internet appears to be a new tool which consumers can use to great economic
benefit.

Consumers can purchase goods online, which may be a source of convenience even for goods available locally. In addition, the Internet has also allowed consumers access to a vastly expanded variety of products, the ability to trade with many other consumers regardless of their geographic proximity, and the freedom to engage in all of these activities at any time of the day from any location.

The Internet drastically reduces search costs and aids in price comparisons for homogeneous goods. This ease of comparison requires firms to compete more on price then when consumers had to physically search across stores or manufacturers. Research findings show 
substantial price declines for consumers who search online. However, industries threatened by the intense price competition from the Internet may lobby for state-level protection. Such regulations, if successful, would prevent this aspect of the Internet from benefiting consumers. Firms are also likely to engage in other tactics to raise search costs to more profitable levels, such as attempting to fool search engines into providing advantageous placement or to convince customers to upgrade to a more expensive product. Goods with unobserved quality will be more difficult to trade online, and we should expect to see third-party rating schemes develop to facilitate trade in these markets.

In addition to obvious economic gains from purchasing online and from lower prices, the Internet creates utility gains for consumers from increased efficiency in daily tasks. Commercial enterprises, government agencies, and nonprofit organizations can all use the Internet to provide consumers with useful information. Directions, regulations, calendars, etc. can be made available at any time, in great detail, from the consumer's home. Informational websites supported by advertising or subscriptions provide consumers with weather, product data, sports information, and so on. Consumers who have an interest not supported locally can use the Internet to obtain information and communicate with other like-minded individuals. All of these features of the Internet are likely to save consumers time and increase the quality of daily life, although this is hard to measure.

While the Internet has the potential to benefit everyone, some consumers gain disproportionately. Consumers who face time pressure during a normal working day, consumers who are in the minority in terms of ethnicity, tastes, or hobbies, and consumers with high search costs for any reason will particularly benefit from use of the Internet. Overall, the technological innovation of the Internet and the associated business model innovation are delivering substantial benefits to consumers.

\section{Endnotes}

Contact information for author: Box 208200, New Haven, CT 06520-8200. E-mail address: fiona.scottmorton@yale.edu. The author gratefully acknowledges helpful comments from the editors and excellent research assistance from Carlos Rocha.

1. From www.internetworldstats.com consulted 2/15/2005.

2. The economic and social impacts of electronic commerce. OECD report 1999. 
3. Nielsen ratings summarized at http://www.nua.net/surveys/how_many_online/
n_america.html visited 3/11/05.

4. InternetWorldStats.com has these figures.

5. Nie (2004) Stanford Center for the Quantitative Study of Society.

6. http://www.websiteoptimization.com/bw/ accessed 3/11/05 and relying on original data from Nielsen/NetRatings, Jupiter Research, Ipsos-Reid, and others.

7. www.pewinternet.org visited $3 / 18 / 2005$ shows that Internet use is lower for Hispanic ( 63 percent) and black Americans ( 51 percent) than for non-Hispanic whites
(68 percent).

8. http://www.priceline.com/ and http://www.google.com/intl/en/ads/index.html.

9. http://travel.state.gov/ and www.masstimes.org.

10. Typically, however, the retailers that sell digital entertainment goods are not vertically integrated into their production, so in that way they do not resemble the other businesses in this category. Rather, these sites sell music produced by multiple artists and labels.

11. Source: www.peapod.com ("About Our Company" section) viewed 2/17/2005. Ahold (2003) Annual Report http://www.shareholder.com/Common/Edgar/869425/119312504-80768/04-00.pdf.

12. Copyright 2002. The New York Times, January 26, 2002 Saturday; Section C; Column 4; Business/Financial Desk; p. 2.

13. Contact lenses FTC report: http://www.ftc.gov/os/2004/03/040329clreportfinal. pdf, http://www.ftc.gov/opa/2004/03/clrreport.htm. Casket retail FTC report: http://www.ftc.gov/bcp/conline/pubs/services/funeral.htm,http://www.ftc.gov/opp/ ecommerce/anticompetitive/panel/neily.pdf.

14. http://www.nttdocomo.com/corebiz/imode/what/index.html explains i-mode. NTTDoCoMo contracts with content providers who charge users very small fees to buy a ring-tone or horoscope. The user's monthly mobile phone bill from NTT aggregates these tiny payments, and the payments from NTT to content providers are likewise aggregated.

15. www.pwerinternet.org $1 / 25 / 2005$ "A Decade of Adoption: How the Internet has Woven Itself into American Life."

16. Pew Internet \& American Life Project (1/25/2005) "A Decade of Adoption: How the Internet has Woven Itself into American Life," p. 64.

17. ESPN insider provides exclusive content (very detailed stats, NFL simulator, etc), ESPN local (links to sites around the world), real time scoreboard (located on the desktop; no need to refresh information), Wireless scores and alerts (automatically sends information to a wireless device), video (college football and basketball), NFL fantasy, NFL Draft coverage, etc. Cost: $\$ 39.95$ year subscription or $\$ 6.95$ monthly payment.

18. Armstrong (2002), Rochet and Tirole (2001), Anderson and Coate (2001), Rysman
(2002).

19. Harris poll $2004 \# 4$ and poll $2000 \# 30$, Anderson (2001) and Dryburgh (2001).

20. US Dept. of Commerce (2004). 
21. Hubbard (2003) and software products such as @road, www.atroad.com.

22. Dermisi (2004).

23. Information from the eBay websites, http://pages.ebay.com/motors/ ?ssPageName=ML01, and http://pages.motors.ebay.com/services/inspection/ inspection.html visited 2/17/05.

24. http://www.harrisinteractive.com/harris_poll/index.asp?PID $=433$ has the details. Visited 2/17/05.

25. www.pwerinternet.org $1 / 25 / 2005$ "A Decade of Adoption: How the Internet has Woven Itself into American Life."

26. http://www.harrisinteractive.com/harris_poll/index.asp?PID=93 discusses the case of people with diabetes.

27. Data at www.pewinternet.org under "latest trends" and "usage over time."

28. http://www.ftc.gov/os/2002/09/020926testimony.htm.

29. http://www.ftc.gov/opa/2004/03/clrreporthtm and http://www.ftc.gov/os/2004/ 03/040329cireportfinal.pdf viewed 2/17/05.

30. http://www.ftc.gov/opa/2003/07/wine.htm viewed 2/17/05. Wine: http://www. $\mathrm{ftc}$.gov/os/2003/07/winereport2.pdf.

\section{References}

Anderson, Ben, and Karina Tracey. 2001. "Digital Living: The Impact (or otherwise) of the Internet on Everyday Life." American Behavioral Scientist 45(3): 456-475.

Anderson, Simon, and Stephen Coate. 2001. "Market Provision of Public Goods: the Case of Broadcasting." Draft, University of Virginia.

Armstrong, Mark. 2001. "Competition in Two-Sided Markets." Draft, Oxford University.

Brown, Jeffrey R, and Austan Goolsbee. 2002. "Does the Internet Make Markets More Competitive? Evidence from the Life Insurance Industry." Journal of Political Economy 110(3): 481-507.

Brynjolfsson, Erik., Y. Hu, and Michael Smith. 2003. "Consumer Surplus in the Digital Economy: Estimating the Value of Increased Product Variety at Online Booksellers." Management Science 49: 1580-1596.

Brynjolfsson, Erik, and Michael Smith. 2000. "Frictionless Commerce? A Comparison of Internet and Conventional Retailers." Management Science 46(4): 563-585.

Carlton, Dennis, and Judith Chevalier. 2001. "Free Riding and Sales Strategies for the Internet." Journal of Industrial Economics 49: 441-461.

Clay, K., R. Krishnan, E. Wolff, and D. Fernandes. 2002. "Retail Strategies on the Web: Price and Non-price Competition in the Online Book Industry." Journal of Industrial Economics 50: 351-367.

Clemons, E., I. Hitt, and L. Hitt. 2002. "Price Dispersion and Differentiation in Online Travel: An Empirical Investigation." Management Science 48(4): 534-549. 
Dermisi, Sofia. 2004. "Internet Reduces the Time Before Lease-up or Sale of Office Properties." Real Estate Review 33(1): 22-28.

Dryburgh, Heather. 2001. "Changing Our Ways: Why and How Canadians Use the Internet." Statistics Canada Report no. 56F0006XIE.

Ellison, Glenn, and Sara F. Ellison. 2004. "Search, Obfuscation, and Price Elasticities on the Internet." NBER Working Paper no. 10570.

Franzen, Axel. 2003. "Social Capital and the Internet: Evidence from Swiss Panel Data." Kyklos 56: 341-360.

FTC Staff Report. 2003. "Possible Anticompetitive Barriers to E-Commerce: Wine." FTC Staff Report. 2004: "Possible Anticompetitive Barriers to E-Commerce: Contact
Lenses."

Hubbard, Thomas. 2003. "Information, Decisions, and Productivity: On Board Computers and Capacity Utilization in Trucking." American Economic Review 93(4): 1328-
1353. Jin, Ginger Zhe, and Andrew Kato. 2004. "Dividing Online and Offline: A Case Study."
Draft, University of Maryland.

Lohse, Gerald, Steven Bellman, and Eric Johnson. 2000. "Consumer Buying Behavior on the Internet: Findings from Panel Data." Journal of Interactive Marketing 14(1): 15-29.

Nie, Norman. 2004. "Ten Years after the Birth of the Internet, How Do Americans Use the Internet in Their Daily Lives?" Report by Stanford Center for the Quantitative Study of
Society.

Pauly, Mark, Bradly Harring, and David Song. 2002. "Health Insurance on the Internet and the Economies of Search." NBER Working Paper no. 9299.

Rainie, Lee, and John Horrigan. 2005. "How the Internet has Woven Itself into American Life." Pew Internet \& American Life Project.

Madden, Mary, and Lee Rainie. 2003. "America's Online Pursuits." Pew Internet \& American Life Project.

Rochet, Jean-Charles, and Jean Tirole. 2001. "Platform Competition in Two-Sided Markets." Journal of the European Economic Association 1(4): 990-1029.

Rysman, Marc. 2002. "Competition between Networks: A Study of the Market for Yellow Pages." Review of Economic Studies 71(2): 483-512.

Scott Morton, Fiona, Florian Zettelemeyer, and Jorge Silva-Risso. 2001. "Internet Car Retailing." Journal of Industrial Economics 49(4): 501-519.

Scott Morton, Fiona, Florian Zettelemeyer, and Jorge Silva-Risso. 2003. "The Effect of the Internet on Car Prices for Women and Minorities." The Journal of Quantitative Marketing
and Economics 1(1):77-92.

Scott Morton, Fiona, Florian Zettelemeyer, and Jorge Silva-Risso. 2005. "A Test of Bargaining Theory in the Auto Retailing Industry." Draft, Yale School of Management.

Sinai, Todd, and Joel Waldfogel. 2003. "Geography and the Internet: Is the Internet a Substitute or a Complement for Cities?" NBER Working Paper no. 10028. 
Taylor, Humphrey. 2000. "How the Internet is Improving the Lives of Americans with Disabilities." Harris Poll \#39, June 7.

U.S. Dept. of Commerce. 2004. "A Nation Online: Entering the Broadband Age." Economics and Statistics Administration.

Zettelmeyer, Florian, Fiona Scott Morton, and Jorge Silva-Risso. 2004. "Cowboys or Cowards: Why are Internet Car Prices Lower?" Draft, Yale School of Management.

Zettelmeyer, Florian, Fiona Scott Morton, and Jorge Silva-Risso. 2005. "The Role of the Internet in Lowering Prices: Evidence from Matched Survey and Auto Transaction Data." Forthcoming in The Journal of Marketing Research, May 2006. 